\title{
LA CONTRIBUCIÓN A LOS GASTOS PÚBLICOS, UN DEBER MÁS ALLÁ DE LA RECAUDACIÓN
}

Contribution to public expenditure: beyond duty to contribute

\section{Miguel Ángel Sánchez Huete}

Profesor de Derecho Financiero y Tributario de la Universitat Autónoma de Barcelona, con anterioridad y durante más de quince años se ha de dedicado al ejercicio profesional de la abogacía. Es Licenciado en Derecho por la Universitat de Barcelona y Doctor por la Universitat Internacional de Catalunya. Dentro de sus líneas principales de investigación y publicación destacan: las infracciones y sanciones tributarias, el uso de sociedades como instrumento de elusión y el análisis de la responsabilidad social desde la perspectiva tributaria. E-mail: miguelangel.sanchez@uab.es

\section{RESUMEN}

En la presente artículo se pretende reflexionar sobre la naturaleza jurídica y el valor ético del deber de contribuir. De una parte, se analiza y defiende el carácter fundamental del deber de contribuir, pues se haya vinculado al valor de solidaridad. Por otra parte, el deber de contribuir se exige de acuerdo a principios jurídicos. A tal efecto se estudia la exigencia ética de tal derecho y en concreto los riesgos de las medias preventivas del fraude.

Con ello deseamos mostrar el carácter, además de jurídico, intrínsecamente valorativo y ético, tanto del deber de contribuir, como de su exigencia. Ambos aspectos -deber y exigencia- son parte de una misma dimensión, pero de diversa perspectiva. Con el deber se afirma su vinculación y con la exigencia se estudia el papel del legislador y de la Administración, pero también de sus límites

Palabras clave: Deber de contribuir. Solidaridad. Dignidad. Derechos fundamentales. Prevención del fraude. Buena fé. 


\begin{abstract}
In the present article aims to reflect on the legal nature and ethical duty to contribute value. On one hand, discusses and defends the fundamental nature of the duty to contribute, as has been linked to the value of solidarity. Moreover, the duty to contribute is required according to legal principles. Ethics requiring such a right is studied and, in particular, the risks of fraud preventative measures.

With this we want to show the character, plus legal inherently evaluative and ethical duty to contribute both as your requirement. Both aspects-duty and requirement-are part of the same dimension, but different perspective. With the duty states and its links with the requirement of the legislature and the role of government, but its limits are studied.
\end{abstract}

Keywords: Duty to contribute. Solidarity. Dignity. Fundamental Rights. Fraud PREVENTION. GOOD FAITH.

SumARIO: 1. Introducción y objeto de estudio. 2. El carácter fundamental del deber de contribuir. 2.1. Deber de contribuir y derechos fundamentales. 2.2. El valor del deber de contribuir. 3. La exigencia del deber y sus riesgos. 3.1. La aceptación y exigencia ética de la deuda tributaria. 3.2. La prevención del fraude y sus riesgos. Conclusiones.

\title{
1. INTRODUCCIÓN Y OBJETO DE ESTUDIO
}

En el contexto de crisis actual resulta más necesario que nunca recordar que la tributación es instrumento de redistribución y elemento esencial para el funcionamiento de los servicios y prestaciones del Estado social. Pocas normas como las tributarias evidencian más claramente el compromiso ético de una sociedad. Son normas éticas porque son instrumento de solidaridad y redistribución. Lejos quedan concepciones que las ideaban únicamente como normas negativas, de carácter limitativo e interpretación restrictiva, también son disposiciones que comportan una perspectiva positiva, de solidaridad y redistribución de los recursos de una comunidad.

La solidaridad resulta un valor que evidencia una ética laica cuya principal manifestación resulta un deber: el deber de contribuir. El carácter fundamental de dicho deber no acostumbra a ponerse de manifiesto, a pesar de tener por base uno de los valores que junto a la libertad, seguridad e igualdad, cimentan los derechos así considerados. Afirmar dicho carácter fundamental tiene como correlato el estableci- 
miento de las medidas necesarias para su garantía y para protegerlo de los peligros que encierran las conductas insolidarias. Para tal finalidad se han de utilizar normas preventivas ante la situación de riesgo potencial que suponen algunos comportamientos. Ahora bien la adopción de tal función normativa supone una especial injerencia en la esfera patrimonial y personal de los obligados, de ahí que su regulación ha de ser adecuada y proporcional al fin perseguido.

Guiándonos por tales orientaciones pretendemos tanto enfatizar el carácter fundamental del deber de contribuir como analizar -sobre la base de las normas tributarias del Estado español- las disfunciones que puede suponer el abuso de las normas preventivas del fraude.

El anterior objetivo nos exige plantear, en primer lugar, la relación existente entre el deber de contribuir y los derechos humanos para mostrar su carácter fundamental. En segundo lugar, procederemos a abordar la problemática de la exigibilidad de tal deber. Para ello tendremos en consideración su carácter ético, la necesidad de instrumentos adecuados para prevenir el fraude, y la proporcionalidad de las medidas para tal fin. Con ello intentaremos evidenciar el carácter, además de jurídico, intrínsecamente valorativo y ético tanto del deber de contribuir, como de la necesidad de establecer límites ante determinadas visiones preventivas del fraude. Ambos aspectos -deber y exigencia- son parte de una misma dimensión, pero de diversa perspectiva; en tanto que deber, se afirma su vinculación y; en tanto que exigencia, se alude al poder del legislador y de la Administración, pero también a sus límites.

Dicho análisis supone un abordaje jurídico centrado en la legislación y doctrina española en donde tendrá especial relevancia la regulación tributaria establecida en la Constitución de 1978. También, y para el estudio de dicha temática, se adopta un enfoque que conjuga diversas disciplinas jurídicas, el Derecho Tributario y el Financiero en que se inserta, principalmente, pero también la Filosofía del Derecho y el Derecho Constitucional. Todo ello teniendo presente tanto las aportaciones de la doctrina como de la jurisprudencia de nuestro Tribunal Constitucional.

\section{El CARÁCTER FUNDAMENTAL DEL DEBER DE CONTRIBUIR}

Determinar el carácter de fundamental del deber de contribuir ha de partir de su concreción en los derechos de los cuales se predica. O sea, ¿cuál es el elemento que permite calificar a unos derechos como fundamentales? Y a renglón seguido, ¿puede predicarse también de un deber jurídico?, ¿existe alguna correlación entre la afirmación de unos y otros?

Los derechos tienen que ver con los valores sobre los que se basan, pero también con las necesidades sentidas como esenciales. Dichas necesidades son mutables en el tiempo y aparecen vinculadas a un contexto histórico. Así se afirma que el catálogo de derechos humanos se apoya en un sistema de valores dinámico que 
está conectado con necesidades básicas generalizables ${ }^{507}$. Tal dinamismo, junto a la ampliación de su concepto y la fuerte carga ideológica que los acompañan, ha llevado a hablar de una cierta indeterminación y ambigüedad de su sentido ${ }^{508}$. De ahí que a efectos terminológicos, y también en aras de concretar su contenido, se ha preferido denominar a los derechos humanos como fundamentales. Así PECES-BARBA MARTINEZ considera que la utilización del término de derechos fundamentales resulta mejor que el de derechos humanos pues posee una menor ambigüedad y aparece desprovisto de bagajes ideológicos -se desconecta de las pretensiones morales asociadas al derecho natural-. Dicha designación también se vincula a un reconocimiento constitucional o legal y refuerza su dimensión ética ${ }^{509}$. La idea básica que anima a tales derechos es entenderlos como fundamentadores del sistema jurídico -político del Estado de Derecho. En tanto que derechos subjetivos resultan posiciones jurídicas de atribución, ya sea como poder, o ya sea como esfera de libertad, que tiene todo individuo por razón de su humanidad.

Los derechos fundamentales aparecen, en un primer momento histórico, configurados como posiciones jurídicas individuales frente al Estado, como esferas de libertad que garantizan la no injerencia de éste en espacios de libertad. Será más tarde cuando se conciban como derechos a la prestación, derechos que comportan un hacer positivo de los poderes públicos.

En origen los derechos considerados como fundamentales poseen una función tuitiva que pretende garantizar la autonomía personal y la independencia moral. Por ello una de las funciones básicas de los derechos es la de garantizar unos espacios exentos en donde sus titulares puedan actuar libremente ${ }^{510}$. Dicha perspectiva garan-

${ }^{507}$ RODRIGUEZ PALOP, María Eugenia. Claves para entender los nuevos derechos humanos. Madrid: Catarata. 2011, p. 37.

${ }^{508}$ MARTINEZ MORÁN, Narciso y DE CASTRO CID, Benito (Coordinadores). Diecisiete lecciones de Teoría del Derecho. $2^{\text {a }}$ edición, Madrid: Uned Editorial Universitas, 2011, p. 211.

509 PECES-BARBA MARTINEZ, Gregorio. Lecciones de Derecho Fundamentales. Madrid: Dykinson. 2004, p. 28. PEREZ LUÑO remarca también que el término de derechos humanos posee unos contornos más amplios e imprecisos al aludir a derechos y libertades reconocidos en declaraciones y convenios internacionales que, debiendo ser objeto de positivación, no lo han sido. Por el contrario los derechos fundamentales poseen un concepto más estricto y preciso se trata siempre de "derechos delimitados espacial y temporalmente, cuya denominación responde a su carácter básico o fundamentador del sistema jurídico político del Estado de Derecho". (PEREZ LUÑO, Antonio Enrique. Los derechos fundamentales. $8^{\text {a }}$ edición, Madrid: Tecnos. 2004, p. 46-47.)

510 Ver PECES BARBA que señala que son cuatro las dimensiones de los derechos: la garantizadora o protectora, la participativa, la promocional y la de disenso (PECES-BARBA MARTINEZ, Gregorio. Lecciones de Derecho Fundamentales. Madrid: Dykinson. 2004, p. 278). DIÉZ PICAZO habla de la función de protección -que salvaguarda al individuo- y de legitimación -como criterio de diferenciación de lo justo e injusto-. (DIÉZ PICAZO, Luís 
tista comporta configurarlos como un límite al poder que garantizan la autonomía, o sea, un deber de abstención de los poderes públicos. Esta idea de libertad, asociada a la no injerencia de un poder público, se ha de entender en su sentido primigenio: como límites a un poder público autoritario no democrático. Resulta indicativo, para apreciar de donde venimos conceptualmente y denotar algunas rémoras que persisten, el confrontar el sentido de las libertados con el sentido primero de la tributación.

El tributo nace como manifestación del poder del Estado, concretamente del poder militar, en tanto que se imponía a los pueblos vencidos. Era así concebido como un mero ejercicio del poder autoritario y de la fuerza y que, por consiguiente, no precisa fundamentación o principio regulador para su exigencia ${ }^{511}$. La obligada contribución se manifiesta como un deber derivado del ejercicio de la fuerza unilateral, en donde quien paga la carga tributaria es un vencido, sin más derechos que los concedidos graciablemente. Tal concepción contrasta con la idea actual de tributo vinculada a la autoimposición, al reconocimiento del estatus de ciudadano, y a su ordenación en base a principios jurídicos.

El tributo es fruto de la autoimposición a través de normas dictadas en parlamentos democráticos por ciudadanos. Ciudadanos, con posiciones jurídicas de atribución y vinculación preestablecidas normativamente. $\mathrm{Y}$ en donde la carga tributaria se establece en base a principios constitucionalizados que fundamentan una imposición justa.

\subsection{DERECHOS FUNDAMENTALES Y DEBER DE CONTRIBUIR}

La libertad, asociada a los derechos fundamentales, ha de entenderse conformada de acuerdo con la convivencia social, de ahí que no resulta absoluta. No perjudica o contraría su existencia las modulaciones derivadas de la propia decisión manifestada formalmente a través de la ley, expresión de los representantes libre y democráticamente elegidos.

El paso de una situación de sujeción, propia de súbditos, a una posición jurídica de atribución y vinculación, propia de ciudadanos, tiene que ver con el principio de legalidad como manifestación de autoimposición. En tal escenario, el fundamento de la tributación y su régimen a través de principios resulta básico, pues no hay lugar en el Estado de Derecho para un poder sustraído de toda regla ${ }^{512}$. En

María. Sistema de derechos fundamentales. $4^{\mathrm{a}}$ edición. Madrid: Civitas Thonsom-Reuters, 2013, p. 37).

${ }^{511}$ MARTIN QUERALT, Juan, LOZANO SERRANO, Carmelo, TEJERIZO LOPEZ, José Manuel y CASADO OLLERO, Gabriel. Curso de Derecho Financiero y Tributario. Madrid: Tecnos. 2007, p. 214.

${ }^{512}$ MARTIN QUERALT, Juan, LOZANO SERRANO, Carmelo, TEJERIZO LOPEZ, José Manuel y CASADO OLLERO, Gabriel. Curso de Derecho Financiero y Tributario. Madrid: Tecnos. 2007, p. 214. 
palabras de BAYONA DE PEROGORDO y SOLER ROCH lo más característico del poder soberano en el Estado constitucional es que se trata de un poder sometido a la Constitución, pues ésta es al mismo tiempo fundamento y límite de la actuación del órgano que detenta la supremacía financiera ${ }^{513}$.

La doctrina de nuestro Tribunal Constitucional -Sentencia del Tribunal Constitucional (en adelante STC) 3/2003, de 16 de enero- señala que como consecuencia directa del principio de autoimposición surge el derecho del ciudadano, no sólo a consentir los tributos, sino también a conocer su justificación y el destino a que se afectaba. Tal derecho se recogió tempranamente en la Bill of Rights de 1969, se expresó claramente la Declaración de los Derechos del Hombre y del Ciudadano de 1789 (art. 14), y se estableció nuestra Constitución de Cádiz de 1812 (art. 131) (14 $^{514}$ El principio de autoimposición implica, en palabras del Tribunal Constitucional, que "[...] cuando un ente público impone coactivamente una prestación patrimonial a los ciudadanos, cuente para ello con la voluntaria aceptación de sus representantes" (STC 185/1995, de 14 de diciembre, FJ 3).

El principio de legalidad vinculado a su legitimidad democrática, a la idea de autoimposición y de control, evidencian la existencia de un deber de contribuir fuera de los parámetros de la sujeción y subordinación tradicionales. Es un deber

${ }^{513}$ BAYONA DE PEROGORDO, Juan José y SOLER ROCH, María Teresa. Compendio de Derecho Financiero. Alicante: Librería Compas, 1991, p. 136.

${ }^{514}$ Mas extensamente dicha resolución en su Fundamento Jurídico $3^{\circ}$ analiza el entronque histórico e imbrica tales comentarios en el análisis de la institución presupuestaria "Los primeros presupuestos, así pues, constituían la autorización del Parlamento al Monarca respecto de los ingresos que podía recaudar de los ciudadanos y los gastos máximos que podía realizar y, en este sentido, cumplían la función de control de toda la actividad financiera del Estado. En la segunda mitad del siglo XIX, sin embargo, cuando los tributos se convierten en la principal fuente de financiación de los Estados, se produce un desdoblamiento del principio de legalidad financiera, fenómeno que en nuestro Estado tiene lugar con la Constitución de 1869. La Ley de presupuestos, en efecto, pasa de establecer una autorización respecto de los ingresos a recoger una mera previsión de los mismos, en la medida en que su establecimiento y regulación se produce mediante otras normas de vigencia indefinida (principio de legalidad tributaria). Sin embargo, respecto de los gastos la Ley de presupuestos mantiene su carácter de autorización por el Parlamento, autorización que es indispensable para su efectiva realización (principio de legalidad presupuestaria). Este principio de legalidad presupuestaria dio lugar a la Ley provisional de administración y contabilidad de la hacienda pública de 25 de junio de 1870. Así, la conexión esencial entre presupuesto y democracia parlamentaria debe ser destacada como clave para la resolución de este recurso de inconstitucionalidad. El presupuesto es, como hemos visto, la clave del parlamentarismo ya que constituye la institución en que históricamente se han plasmado las luchas políticas de las representaciones del pueblo (Cortes, Parlamentos o Asambleas) para conquistar el derecho a fiscalizar y controlar el ejercicio del poder financiero: primero, respecto de la potestad de aprobar los tributos e impuestos; después, para controlar la administración de los ingresos y la distribución de los gastos públicos". 
consentido cuya necesidad se evidencia en establecer las condiciones materiales para que la persona se desarrolle como tal.

En definitiva, las decisiones sobre la propia libertad no cuestionan o niegan su esencia, pues el individuo la conforma en relación a las necesidades de la vida en comunidad. De la misma manera, la obligación que se autoimpone el individuo en la forma del deber de contribuir no resulta privación de la libertad. Es más, la contribución conlleva también una perspectiva positiva de solidaridad ${ }^{515}$. Solidaridad, como valor básico del individuo y de su coexistencia en una comunidad. En tal contexto se ha de tener presente que la concepción y la dimensión de tal deber fundamental determina la propia significación del poder público. Pues existe una íntima relación entre el papel de los derechos y el modo de organizar y ejercer las funciones estata1 es ${ }^{516}$.

Desde la perspectiva del obligado, la tributación es contemplada tradicionalmente como un mero costo. En ocasiones, con la afirmación de que el tributo es un límite a la propiedad se pretende enfatizar no una mera visión negativa del mismo, sino su necesidad. Los tributos son la contrapartida más evidente al disfrute de determinados estándares de derechos individuales y sociales. Normalmente una mayor contribución garantiza a la colectividad, y no necesariamente a su pagador, un mayor nivel de prestaciones y derechos. Es así recurrente la expresión de que el tributo resulta el precio de la libertad ${ }^{517}$, aun cuando el tributo ni jurídicamente es precio, ni la libertad el único de los derechos asociados a su pago. El tributo hace posible la existencia material de las estructuras de organización básicas que permiten hablar de lo público, por compartido y colectivo. De ahí su necesidad en los Estados contemporáneos.

La deuda fiscal no es sólo costo o límite patrimonial también es contribución que expresa y vehicula el valor de solidaridad ciudadana. Solidaridad que, configurada como deber, resulta el correlato a los derechos cívicos que nos corresponden por vivir en una concreta comunidad política, en un concreto Estado social. Ambas posiciones, de atribución -derechos cívicos- y vinculación -deber de solidaridad-, resultan genéricas e inespecíficas ya que ex ante no se concretan las prestaciones que las integran, hasta que no se configuran en posiciones jurídicas definidas de presente. Dicha dicotomía y correlación permiten visualizar que la solidaridad no es un mero altruismo voluntarista, y explica su necesidad y exigencia racional, en clave jurídica, como valor, principio y deber ${ }^{518}$. Con ello se pone de relieve que el tributo, además

${ }^{515}$ Ver PEREZ ROYO, Fernando. Derechos Financiero y tributario. Parte General. Madrid: Thonson-Civitas. 2005, p. 104.

516 PEREZ LUÑO, Antonio Enrique. Los derechos fundamentales. $8^{\text {a }}$ edición, Madrid: Tecnos. 2004, p. 20.

517 Ver TIPKE, Klaus. Moral tributaria del Estado y de los contribuyentes. Madrid: Marcial Pons, 2002, p. 56-57.

${ }^{518}$ Ver a este respecto ROZAS VALDÉS, José Andrés. "Nota preliminar", en Franco GALLO. 
de su función instrumental, al procurar la realización de otros derechos, posee una función propia y autónoma a través de la solidaridad ${ }^{519}$.

Es tradicional contemplar a la contribución como un límite a otros derechos básicos como la propiedad ${ }^{520}$. Limite que aparece asociado al ejercicio de poder por el Estado, al que los derechos fundamentales -en origen- están llamados a poner coto. Pero el deber de contribuir no es un mero ejercicio de poder del Estado, como reiteramos, es la plasmación de un valor fundamental para vida colectiva y el ejercicio de los demás derechos: la solidaridad. El ejercicio de tal deber se disciplina en un fundamento y régimen de principios normalmente positivados en normas constitucionales, en nuestro caso en el art. 31 de la Constitución Española (en adelante CE).

Los principios de derecho tributario consagran valores y postulados fundamentales; desde la perspectiva formal, el principio de legalidad, y desde la material; los principios de reparto de la carga tributaria orientados en función de la capacidad económica, de la igualdad, la generalidad, la progresividad y la no confiscatoriedad. Tanto en los derechos como en los deberes públicos se imbrican valores básicos y compartidos por la sociedad que permean todas las expresiones normativas, también en el ámbito tributario. En tal sentido la STC 53/1981, 11 de abril señala al referirse a los derechos fundamentales que "son los componentes estructurales básicos tanto del conjunto del ordenamiento jurídico objetivo como de cada una de las ramas que lo integran, en razón de que son expresiones jurídicas de un sistema de valores que, por decisión del constituyente, han de informar la organización jurídica y política".

La solidaridad se ha configurado como un valor que encuadra una cierta ética laica y cuyo punto de partida es el reconocimiento de la realidad del otro y la

Las razones del Fisco. Ética y justicia en los tributos. Madrid: Marcial Pons, 2012, p. 16.

519 Se ha de tener presente que en el tributo convergen diversas finalidades; la que podríamos denominar intrínseca, que supone obtener recursos dinerarios para financiar gastos públicos y; la asociada a la anterior, en tanto que pretende, además de la recaudación, determinadas finalidades sociales, como la redistribución de la riqueza o la solidaridad. Ver VARONA ALABERN, Juan Enrique. Extrafiscalidad y dogmática tributaria. Madrid: Marcial Pons, 2009, p. 157-158 y CAZORLA PRIETO, Luís María. Derecho Financiero y Tributario. Parte General. Pamplona: Aranzadi, 2002, p. 41.

520 Al hablar de derechos humanos y tributación resulta recurrente enfatizar los espacios de no injerencia que poseen la ciudadanía y que el poder tributario no puede vulnerar. En tal sentido se defiende derechos a las personas jurídicas, asegurar un estatuto jurídico del contribuyente, también se declaran límites al poder del Estado sometido al principio de legalidad o regido por el de igualdad, de manera que la misma capacidad tribute de manera semejante. En tal sentido se afirma que la tributación ha de asegurar la libre circulación y un mínimo existencial y no puede perjudicar otras libertades (Ver Conclusiones de XX Jornadas Latinoamericanas de Derecho Tributario, Salvador (Bahía) - Brasil, 2000, [consultado 5 junio 2014]. Disponible en: http://www.iladt.org/frontend/ResolutionPage.aspx. 
consideración de sus problemas como propios, susceptibles de resolución con intervención de los poderes públicos y de los demás ${ }^{521}$. El deber de contribuir se basa en el valor de la solidaridad, ínsito y connatural de las sociedades en que se reconocen derechos fundamentales. En tal sentido, el ordenamiento español declara la solidaridad como valor superior del ordenamiento jurídico - art. 1 de la CE- base de derechos fundamentales y criterio de interpretación de los mismos. La solidaridad participa de los rasgos generales de la cultura jurídica y política en que surgen tales derechos. Si bien, y a diferencia de los demás valores, la solidaridad legitima la creación de deberes, y no directamente la creación de derechos. Llegados a este punto cabe interrogarse sobre la posibilidad de considerar a tal deber como fundamental.

\subsection{El VALOR DEL DEBER De CONTRIBUiR}

Somos del parecer - e intentaremos argumentarlo seguidamente- que el carácter fundamental del deber de contribuir puede predicarse en la medida que aparezca integrado como contenido propio de la dignidad de la persona ${ }^{522}$. Pues la dignidad resulta consustancial a los derechos fundamentales por su relación con la propia esencia de la persona. De ahí, que si puede incluirse el deber de contribuir como contenido de la dignidad de la persona podrá ser considerado como fundamental. Junto a la anterior consideración también se han de tener presente las exigencias que supone la existencia, dentro de los derechos fundamentales, de los derechos con contenido prestacional. Pues su realización demandan recursos materiales que sin la solidaridad, vehiculada a través de la tributación, no son posibles en nuestros contextos.

Las anteriores perspectivas manifiestan las diversas funciones atribuidas al deber de contribuir; una función autónoma - escasamente puesta de relieve- en tanto que lo vincula con el valor de solidaridad y lo imbrica en la dignidad de la persona; y otra función instrumental en la medida que resulta un medio para allegar recursos que han de hacer posible la realización material de los derechos reconocidos ${ }^{523}$.

${ }^{521}$ En tal sentido PECES-BARBA MARTINEZ, Gregorio. Lecciones de Derecho Fundamentales. Madrid: Dykinson. 2004, p. 178.

${ }_{522}$ Por el contrario DIÉZ PICAZO es de la opinión que los deberes constitucionales no son correlativos de los derechos fundamentales. Su enunciación posee un valor simbólico que sugiere que los beneficios de los ciudadanos no son gratuitos y se limitan a dar cobertura constitucional a la intervención del el legislador en algunos ámbitos de libertad (DIÉZ PICAZO, Luís María. Sistema de derechos fundamentales. $4^{\mathrm{a}}$ edición. Madrid: Civitas Thonsom-Reuters, 2013, p. 54). Sin duda tal perspectiva contempla al deber más como límite a la propiedad y a otros derechos y libertades que como vinculo con sustantividad propia.

${ }^{523}$ Los deberes acostumbran a aparecer en relación con los derechos fundamentales, como un reflejo de los mismos, como límites a la acción pública, pero no con una configuración autónoma. No obstante también existen deberes independientes, sobre la base de derechos, es el caso de bienes que se corresponden con derechos positivos que exigen la intervención del Estado -salud, educación, trabajo, vivienda...- (En tal sentido PALOMBELLA, Gianluigi. 
La idea de dignidad singulariza a la persona como algo diferente y distinto a cualquier otra realidad, dicha consideración le confiere una protección primaria e incluso superior a la propia de la comunidad en que se organiza. La dignidad, como concepto jurídico, aparece con fuerza en el derecho nacional e internacional vinculado a la defensa de los derechos humanos en el siglo pasado, y adquiere un fuerte protagonismo a partir de la Segunda Guerra Mundial ${ }^{524}$. En tal sentido el Tribunal Constitucional afirma que la Constitución Española salvaguarda aquellos derechos "que pertenecen a la persona en cuanto a tal y no como ciudadano o, dicho de otro modo aquellos que son imprescindibles para la garantía de la dignidad humana[...]" (STC 91/2000 de 20 de marzo). El ser humano no es, no puede ser, instrumento para otra finalidad, ni sus derechos ceden ante los intereses del Estado o de la sociedad.

En tal sentido los derechos humanos son derechos subjetivos originarios -pre sociales- ligados a la propia esencia de la persona ${ }^{525}$. Así se puede deducir de la dicción del art. 10.1 de la Constitución Española al afirmar que "La dignidad de la persona, los derechos inviolables que le son inherentes, el libre desarrollo de la personalidad, el respeto a la ley y a los derechos de los demás son fundamento del orden político y de la paz social." En tal configuración prima tanto su visión como límite a la actuación de los poderes públicos, espacio de libertad en donde no pueden intervenir, como evidencia un reconocimiento previo y superior al efectuado por un concreto ordenamiento positivo. La regla establecida implica un "valor espiritual y moral inherente a la persona ha de permanecer inalterada en cualquier situación en que la persona se encuentre" (STC 53/1985, 11 de abril F.J. 8) $)^{526}$.

El sentido de dignidad se relaciona con un ámbito de inmunidad al poder del Estado, pero también se asocia con garantizar condiciones de existencia física para la vida humana. Es así que tal cualidad se esgrime contra las violaciones de

"De los derechos y de su relación con los deberes y los fines comunes". Derechos y libertades, $\mathrm{n}^{\mathrm{o}}$ 17, época II, junio 2007, p. 130).

${ }^{524}$ Ver GOMEZ SANCHEZ, Yolanda. "Dignidad y ordenamiento comunitario" en Revista de Derecho Constitucional Europeo, ${ }^{\circ}$ 4, 2005, [consultado: 4 junio 2014] Disponible en internet en http://www.ugr.es/ redce/REDCE4/articulos/09yolanda.htm.

${ }^{525}$ Existen dos concepciones de derechos humanos no necesariamente incompatibles, las material que pone el acento en el contenido de los mismos, lo crucial no es cómo se regulan sino su carácter universal, y la formal que prima la fortaleza de tales derechos al recogerse en una norma supralegal como es la constitución (DIÉZ PICAZO, Luís María. Sistema de derechos fundamentales. $4^{\mathrm{a}}$ edición. Madrid: Civitas Thonsom-Reuters, 2013, p. 31).

${ }^{526}$ También la STC 120/1990, 27 de junio -FJ. 4- afirma que "[...] la dignidad ha de permanecer inalterada cualquiera que sea la situación en que la persona se encuentre, también, qué duda cabe, durante el cumplimiento de una pena privativa de libertad, como repetidamente se cuida de señalar la legislación penitenciaria, constituyendo, en consecuencia, un minimun invulnerable que todo estatuto jurídico debe asegurar, de modo que, sean unas u otras las limitaciones que se impongan en el disfrute de derechos individuales, no conlleven menosprecio para la estima que, en cuanto ser humano, merece la persona $[\ldots]$ ". 
derechos personales relacionados con la vida y condiciones físicas de la persona ${ }^{527}$. Ahora bien también cabría plantear si dentro de la idea de dignidad caben las condiciones de vida material, aquellas condiciones que puedan considerarse inherentes a la propia existencia del ser humano. Este interrogante plantea si los derechos sociales, económicos y culturales son inherentes al ser humano, y en qué medida caben incluirlos en el concepto de la dignidad. No obstante, y al margen de tal planteamiento -que excede de nuestro objeto-, queda patente que en la medida que se requieran medios materiales para garantizar los derechos vinculados a la existencia física -el derecho a la vida o a la integridad- se hace necesaria la existencia de un deber de solidaridad. Solidaridad, no como mero altruismo, sino como conditio sine qua non de la existencia y reconocimiento de derechos fundamentales.

La realización de muchos derechos fundamentales tal y como se conciben precisan de la solidaridad. Sin ella no pueden existir aquellos. Pero también a la inversa, sin tales derechos no puedan darse las condiciones para que el deber de contribuir sea posible. Tal faceta configura a la solidaridad en que se imbrica el deber de contribuir como un aspecto básico, más allá de su reconocimiento instrumental de procurar medios materiales. Pues entre los derechos también existe una interdependencia en donde difícilmente pueden ser pensados unos sin la coexistencia de los otros

Por consiguiente para garantizar tanto la dignidad existencial, como la dignidad en las condiciones materiales de vida, se precisa de la solidaridad de los miembros de una comunidad. Solidaridad cuya manifestación más importante en las sociedades contemporáneas se arbitra a través del deber de contribuir a los gastos públicos. Resulta así que dicho deber deviene fundamental, no tan sólo para garantizar la eficacia y el reconocimiento material de los derechos de las personas, sino como aspecto ínsito a su propia existencia.

Pero, además y como venimos afirmando, los derechos fundamentales no se agotan en libertades o espacios de no injerencia de los poderes públicos, también pueden adoptar la técnica de los derechos de prestación -derecho a la tutela judicial efectiva, derecho a la enseñanza pública obligatoria...-. A este respecto se ha de tener presente la existencia de tres generaciones de derechos; la primera, la de los derechos civiles y políticos; la segunda, la de los derechos económicos y culturales; y la tercera, la de los derechos económicos, al desarrollo y a la solidaridad ${ }^{528}$. Estas

${ }^{527}$ Ver doctrina citada en GOMEZ SANCHEZ, Yolanda. "Dignidad y ordenamiento comunitario" en Revista de Derecho Constitucional Europeo, no 4, 2005. [consultado: 4 junio 2014] Disponible en internet en http://www.ugr.es/ redce/REDCE4/articulos/09yolanda.htm.

${ }^{528}$ A decir de PEREZ LUÑO dentro de la Constitución económica se ubican el deber de tributar, los derechos y deberes que delimitan el régimen de la propiedad, la libertad de empresa, las relaciones laborales y de seguridad en tanto que resultan el soporte material del ejercicio y actuación de los derechos fundamentales. (PEREZ LUÑO, Antonio Enrique. Los derechos fundamentales. $8^{\text {a }}$ edición, Madrid: Tecnos. 2004, p. 20. Existen diversas clasificaciones de 
últimas generaciones -segunda y tercera- se hayan integradas derechos que no tienen como objeto un deber de abstención de los poderes públicos, sino que comportan un deber positivo de hacer.

De lo anterior se evidencia que los derechos fundamentales en la actualidad no son meros derechos negativos o de no injerencia frente al Estado, son derechos subjetivos que tienen como correlato deberes de actuación del éste. Así afirma la STC 53/1981, 11 de abril que "los derechos fundamentales no incluyen solamente derechos subjetivos de defensa de los individuos frente al Estado, y garantías institucionales, sino también deberes positivos por parte de éste [...]". Las diversas generaciones de derechos han supuesto una ampliación de las necesidades económicas para poder ser materialmente sustentados y, consecuentemente, una ampliación del deber de contribuir. En tal tesitura la necesidad de la solidaridad para allegar recursos resulta clara, solidaridad que se arbitra a través de un concreto deber jurídico. Desde tal perspectiva nuevamente se hace necesario concebir al deber de contribuir como deber básico, si bien con un carácter más instrumental, para la garantía de los derechos prestacionales reconocidos.

El deber de contribuir constituye el presupuesto, material y lógico, para el reconocimiento y eficacia de unos estándares de derechos y libertades que se consideran fundamentales en nuestras sociedades contemporáneas. Existe una estrecha imbricación entre la proclamación de dicho deber, su eficacia y adecuación a principios que garanticen su justicia, con los derechos que se reconocen. De ahí que las conductas que perjudican el deber de contribuir indirectamente perjudican el sustrato material que garantiza una adecuada aplicación de los derechos reconocidos. Se trata de vasos comunicantes: los derechos precisan de medios públicos para su aplicación, y éstos, se obtienen mediante el deber de contribuir. Atendiendo a tal relación la transgresión de tal deber, anclado en la solidaridad ciudadana, supone también erosionar los derechos fundamentales reconocidos. Dicho deber evidencia una importante función instrumental -en la medida que salvaguarda los derechospero ello no puede llevarnos a ignorarse el valor intrínseco y propio que vehicula -la solidaridad-. Tal interrelación no hace menor o inferioriza su reconocimiento, pues al igual que en muchos derechos el reconocimiento de unos necesita de la existencia de otros.

En otro orden de consideraciones, no se puede confundir la eficacia y garantía económica de tales derechos y libertades con sus garantías jurídicas. Las con-

los derechos DIÉZ PICAZO clasifica los derechos según su evolución histórica y atendiendo a su estructura. Vinculados a su evolución histórica, habla de derechos civiles (garantizan ámbitos de autonomía), políticos (garantizan la gestión democrática de los asuntos públicos) y sociales (garantizan las condiciones de vida digna). En relación a su estructura, habla de derechos de defensa en tanto que pueden exigir la no interferencia de los poderes públicos, de participación, ya que facultan realizar actos con relevancia pública, y de prestación al facultar reclamar un beneficio. (DIÉZ PICAZO, Luís María. Sistema de derechos fundamentales. $4^{\mathrm{a}}$ edición. Madrid: Civitas Thonsom-Reuters, 2013, p. 35). 
diciones económicas y las decisiones de gasto no determinan el reconocimiento y garantía jurídica de los derechos fundamentales. Éstos no son contingentes, ni dependen de decisiones presupuestarias. Tal reflexión adquiere una gran importancia en los contextos actuales, pues vivimos tiempos de crisis y mudanza, y los recortes presupuestarios hacen peligrar la eficacia de algunos derechos. En tal tesitura cabria plantear si los derechos reconocidos y las garantías de su aplicación dependen de un presupuesto silente en nuestras Cartas magnas: los derechos se reconocen en la medida que existen recursos económicos que los garanticen.

La respuesta negativa del anterior planteamiento es clara, pues el reconocimiento y las garantías jurídicas no dependen de las medidas económicas. Tal interrogante se resuelve en clave estrictamente jurídica: los derechos fundamentales son derechos subjetivos que vinculan a todos los poderes públicos y son exigibles ante los tribunales -art. 53 de la CE-, de ahí que no es posible subordinar su aplicación a través del gasto. Y si los poderes públicos no garantizan su eficacia, la ciudadanía podrá reclamarlos y exigirlos ante la jurisdicción debiendo, en caso de condena, autorizar las partidas presupuestarias para su satisfacción. No obstante, también es cierto, que la falta de medios hace más frágil su reconocimiento y más frecuentes las reclamaciones para demandar su restauración. Son así, los actuales, momentos de fragilidad para los derechos reconocidos.

\section{LA EXIGENCIA DEL DEBER Y SUS RIESGOS}

A través de los principios contenidos en nuestras constituciones se establecen criterios básicos que conforman la tributación y también su exigencia. En el ámbito español el art. 31 de la Constitución reconoce los principios que rigen y fundamentan el deber de contribuir. También la Ley 58/2003, 17 de diciembre, General Tributaria (en adelante LGT) de en su art. 3 alude a principios de ordenación y aplicación, reiterando algunos de los reconocidos Constitucionalmente.

Los principios de ordenación del sistema tributario suponen mandatos al legislador para el establecimiento de los tributos de acuerdo, básicamente, a los principios constitucionalizados de carácter material y formal. Los primeros, atienden al reparto de la carga tributaria: justicia, capacidad económica, generalidad, igualdad, progresividad y no confiscatoriedad. Y, como principio formal, se reconoce el de legalidad, que procura garantías y control.

Los principios de aplicación suponen directrices a la Administración para que actúe con proporcionalidad, eficacia, limitando los costes indirectos, y asegurando el respeto de los derechos y garantías de los obligados tributarios.

Los principios hacen referencia a valores esenciales o presupuestos lógicos sobre los que se asienta el ordenamiento jurídico ${ }^{529}$. Son elementos básicos

${ }^{529}$ GARCIA DE ENTERRIA, Enrique. y FERNANDEZ, Tomás Ramón. Curso de Derecho Administrativo. Vol I. Madrid: Civitas, 1995, p. 75-76. Estos autores se refieren a ellos como 
referidos a todo el sistema tributario y su contenido resulta exigible jurídicamente respecto del conjunto de impuestos, tasas y contribuciones especiales que conforman el sistema tributario en su globalidad, y no necesariamente de cada uno de sus tributos. En tal sentido ZAGREBELSKY afirma que los principios desempeñan un papel constitutivo del orden jurídico al poseer una eficacia más allá de su significado, evidenciando ideas o pensamientos básicos ${ }^{530}$. Pero también manifiestan una dimensión normativa en su reconocimiento Constitucional. A este respecto se ha de tener presente la cogencia del texto constitucional ${ }^{531}$, pues como afirma el Tribunal Constitucional: "[...] la Constitución, lejos de ser un mero catálogo de principios de no inmediata vinculación y de no inmediato cumplimiento hasta que no sean objeto de desarrollo legal, es una norma jurídica, la norma suprema de nuestro ordenamiento [...]" (STC 16/1981, FJ $\left.1^{\circ}\right)$.

Tales principios resultan limites a la actuación de los poderes públicos y también configuran una esfera positiva que demandan su actuación. Así, por ejemplo, cabe demandar que todos tributen de manera igualitaria, de acuerdo con su capacidad económica, de forma que no exista discriminación por las oportunidades que origina la deslocalización de determinadas rentas -de los capitales principalmenteatendiendo a nuestro contexto globalizado de libre circulación.

Si bien es necesario que los tributos integren los valores que evidencian los anteriores principios, pero también son precisas medidas normativas que favorezcan la percepción ciudadana del fenómeno tributario.

Por un lado, se hace necesaria una mejor regulación y una mayor estabilidad de las disposiciones tributarias. La estabilidad de la normativa ha de hacer posible la seguridad jurídica y la previsibilidad de los cambios, de manera que se eviten modificaciones sorpresivas mediante normas de urgencia. También es preciso una técnica jurídica adecuada que haga inteligible y clara las normas tributarias que, en la gran mayoría de ocasiones, ha de ser aplicada por la ciudadanía y no por avezados técnicos en Derecho ${ }^{532}$.

valores materiales básicos de un ordenamiento jurídico, no son meras tendencia morales sino principios técnicos, fruto de la experiencia jurídica.

${ }^{530}$ ZAGREBELSKY, Gustavo. El derecho dúctil. Ley, derechos, justicia. Madrid: Editorial Trotta. 2009, p. 110.

${ }^{531}$ Ver en tal sentido el art.5 de la Ley Orgánica 6/1985, de 1 de julio, del Poder judicial.

${ }^{532}$ Del art. 4 al 7 de la Ley 2/2011, de 4 de marzo, de Economía Sostenible se evidencia una preocupación por la calidad de la regulación estableciendo en su art. 4 los principios de buena regulación. Así el párrafo 1 del art. 4 señala que "En el ejercicio de la iniciativa normativa, el conjunto de las Administraciones Públicas actuará de acuerdo con los principios de necesidad, proporcionalidad, seguridad jurídica, transparencia, accesibilidad, simplicidad y eficacia. En la iniciativa normativa quedará suficientemente justificada la adecuación a dichos principios." Si bien son normas de eficacia imprecisa por sus consecuencias, al no establecerse sanción concreta al incumplimiento de sus dictados. 
Por otro lado, es necesario visibilizar que el tratamiento tributario -el pago de los tributos y las obligaciones que conlleva- no es una mera carga o dificultad. Para ello, respecto del pago de los tributos, se ha de valorar y mostrar la calidad de los servicios prestados y su vinculación con el ingreso público. Respecto de la carga que suponen las numerosas obligaciones formales de colaboración e información impuestas, se ha de apreciar su lógica y proporcionalidad.

Junto a las anteriores consideraciones se ha de tener en cuenta la exigencia ética que supone el deber de contribuir o, en otros términos, que llevar a cabo su cumplimiento demanda unos condicionantes de valor. No basta el mero poder de realización, es necesario actuar de acuerdo a los fines y principios que legitiman su ejercicio. El prescindir de tal orientación hace que el cumplimiento del deber de contribuir resida más en el efecto - la recaudación- que en la fuerza moral y jurídica que supone su vinculación. Al centrarse en la recaudación se dota de una cierta asepsia moral a la problemática y plantea la cuestión en términos técnicos y de eficiencia. Así no se reprocha tanto el incumplimiento del deber de contribuir como la perdida de recaudación.

En tal línea se muestran dos manifestaciones a tratar en el próximo epígrafe: la denominación y tratamiento como competencia fiscal -como un aspecto mercantil más de concurrencia- que se otorga a los esfuerzos y prácticas de los Estados para captar contribuyentes, y el empleo de mecanismos de cobro disimulados o poco visibles, como si la exigencia del tributo fuera algo vergonzante.

\subsection{LA ACEPTACIÓN Y EXIGENCIA ÉTICA DE LA DEUDA}

En actuales contextos económicos globalizados las rentas de capital -no así las rentas de trabajo- poseen un gran margen de decisión para ubicarse en un territorio u otro. Es por ello que los Estados compiten a la baja en la tributación de tales rentas, con la finalidad de atraer, en esta lógica, a los clientes-contribuyentes. En tal situación los Estados actúan como unos agentes más en un hipotético mercado competitivo de la recaudación.

En tal sentido existen prácticas competenciales que son calificadas por organismos internacionales (OCDE) como competencia fiscal perjudicial -respecto de la existencia de paraísos fiscales-, o "competencia fiscal perniciosa" (Unión Europea), una suerte de competencia desleal. Define el Código de conducta sobre la fiscalidad de las empresas la competencia fiscal perniciosa como aquella que influye o puede influir de forma significativa en la radicación de la actividad empresarial dentro de la Comunidad y que establecen un nivel impositivo notablemente inferior al que se suele aplicar en el Estado miembro afectado ${ }^{533}$. Hemos de reiterar que la

${ }^{533}$ Comunicación de la Comisión al Consejo, al Parlamento Europeo y al Comité Económico y Social Europeo - Fomento de la Buena Gobernanza en el Ámbito Fiscal COM(2009) 201 final. A este respecto se ha de tener presente la preocupación de velar por una competencia 
contribución no solamente se significa por los recursos que allega, sino por el valor que en sí posee. Por ello cabe enfatizar la transgresión ética y jurídica que supone -la causa- más que su efecto, la recaudación.

Relacionado con la anterior reflexión se ha de tener presente que el cumplimiento del deber de contribuir no acostumbra a resultar popular, ni a gozar de prestigio social por lo que el legislador se plantea sortear tales resistencias a través de diversas estrategias, bien vinculando la contribución a fines concretos para buscar una mayor aceptación social, o bien camuflando la contribución como parte de un precio o de la percepción disminuida de un salario o renta.

En primer lugar, las medidas que relacionan la contribución con concretos fines sociales genéricamente aceptados se llevan acabo mediante dos instituciones: la afectación de ingresos a gastos específicos, y el reconocimiento de la extrafiscalidad en el seno del tributo. Por un lado, se establece la afectación de los recursos que se obtienen en la recaudación para aplicarse a concretas finalidades, por ejemplo, a gastos sanitarios, a necesidades escolares o a la investigación médica. Y, por otro lado, se establecen tributos sobre la base de consideraciones extrafiscales. Con ellos se buscan otros fines diversos a la contribución a los gastos generales; el ejemplo más común acostumbra a ser la tributación medioambiental. Tales gravámenes buscan disuadir las conductas más nocivas medioambientalmente -el mayor consumo de productos contaminantes- o incentivar comportamientos más beneficiosos para el medio ambiente -uso de recursos energéticos menos contaminante-.

En segundo lugar, y en ocasiones de manera paralela, existen esfuerzos para que la carga tributaria aparezca camuflada o menos visible. Esta es una suerte de "función camaleónica" que se produce tanto en la tributación directa como indirecta. Dicha función tiene que ver con la confusión del tributo con el precio que se paga por un producto -en el caso de la tributación que grava el consumo, así el IVA-. Pero también con el menor salario o renta que se recibe, es el caso de las retenciones que se efectúan con la finalidad de efectuar pagos anticipados en el Impuesto de la Renta de las Personas Físicas.

Los anteriores son mecanismos que evidencian la existencia de resistencias ante la tributación y lo impopular que supone su exigencia. El deber de contribuir es un deber devaluado éticamente. Tradicionalmente, su cumplimiento no ha comportado el reconocimiento y la estima social asociados a otros, como podría ser cumplir los deberes militares. Obsérvese que mientras que al deber de contribuir se asocia a la idea de gravamen y sometimiento - de manera concordante a su origen histórico-, al deber militar se relaciona con valentía y honor. Tal situación precisa de ser recon-

fiscal de los Estado, tanto eliminando los paraísos fiscales - preocupación sobre todo de la OCDE- como de los regímenes fiscales que pueden considerarse perniciosos -aspecto desarrollados en el contexto de la Unión Europea-. (Ver VALLEJO CHAMORRO, José Ma "La competencia fiscal perniciosa en el seno de la OCDE y la Unión Europea". Revista de economía. $\left.\mathrm{n}^{\circ} 825,2005\right)$. 
ducida y en tal función la educación juega un gran papel

Es preciso fomentar y mejorar la educación tributaria ${ }^{534}$ introduciendo una formación específica no sólo en el sistema educativo formal, en los planes de estudio, sino también incidir en los ámbitos de la educación no formal e informal. Para ello habrá que ofrecer e impulsar una educación que no se limite al saber, a tener unos conocimientos acerca de la tributación, junto a ello, será necesario favorecer los aprendizajes éticos relativos al principio de solidaridad que comporta el pago de los tributos. Especial atención deberá ponerse en la educación informal, la no planificada de forma intencional y explícita pero que permea las relaciones con la Administración.

\subsection{LA PREVENCIÓN DEL FRAUDE Y SUS RIESGOS}

Existen una pluralidad de instrumentos normativos que buscan erradicar el fraude tributario; desde mecanismos punitivos -sanciones administrativas o delitos- de carácter eminentemente represivo, a los preventivos que buscan disuadir al contribuyente de incumplir el deber de contribuir.

Ante la existencia de comportamientos insolidarios se hacen necesarias normas tributarias preventivas o disuasorias que eviten la lesión que supone la falta de ingreso. Ahora bien, al aparece fundamentado el deber de contribuir por principios que lo ordenan, la configuración de las normas preventivas del fraude no es libérrima. Han de ser ponderadas y adecuadas en sus efectos, pues no pueden transmutar el deber jurídico creando una presunción generalizada de mala fe, ni suponer un estado de sujeción propio de súbditos o vencidos. No obstante, antes de desarrollar tales reflexiones y de poner de relieve la importancia de los mecanismos normativos de carácter preventivo existentes, se ha de explicitar algunas estrategias del legislador que buscan luchar contra el fraude a través de medidas que podemos considerar como extravagantes a los fines y valores éticos que han de inspirar su exigibilidad.

\section{A. Los otros instrumentos para combatir al fraude}

En la actualidad apelar al cumplimiento del deber jurídico y cívico de contribuir parece no ser suficiente. En tal sentido la Hacienda Pública se plantea combatir el fraude con mecanismos en donde la exigencia ética de la contribución no parece estar presente -al menos de una manera directa-. Nos referimos a instrumentos como el pago a confidentes para que delaten a los sujetos evasores a cambio de una cuantía dineraria, la adquisición de datos fiscales de las personas consideradas como

${ }^{534}$ Ver al respecto DELGADO LOBO, María Luisa, FERNÁNDEZ-CUARTERO PARAMIO, Marta, MALDONADO GARCÍA-VERDUGO, Ascensión, ROLDAN MUÑIO, Concepción y VALDENEBRO GARCÍA, María Luisa. La educción fiscal en España. Doc. $\mathrm{n}^{\circ}$ 29/05. Madrid: Instituto de Estudios Fiscales, 2005. 
evasores, la organización de loterías fiscales...En el caso de las loterías fiscales se introduce el elemento del azar como estímulo positivo -por el premio que puede obtenerse- para aquellos sujetos que participen aportando facturas de prestaciones de servicios en ámbitos en donde existen normalmente dificultades de control -pequeño comercio, profesionales...-.

La admisibilidad ética de algunas de las anteriores medidas resulta cuestionable. Pues si las normas tributarias evidencian un compromiso ético de la sociedad, los instrumentos y formas de exigencias han de ser coherentes $\mathrm{y}$, en todo caso, respetar los principios que las justifican. En tales parámetros, discutibles y de extravagancia con su contenido ético, se mueven las amnistías fiscales. A este respecto cabe efectuar una breve referencia a la amnistía fiscal de 2012 efectuada por el Estado Español.

El Real Decreto-ley 12/2012, de 30 de marzo, regula en la Disposición adicional primera la declaración tributaria especial, e introduce la que popularmente se ha denominado amnistía fiscal. Amnistía, en tanto que supone dejar de perseguir punitivamente un conjunto genérico de conductas. Y fiscal, derivado del efecto regularizador y ámbito de aplicación. La amnistía fiscal es una medida tributaria, pero también punitiva, mediante la cual las personas que habían ocultado bienes pueden regularizar su situación tributaria pagando el 10\% del valor de los no declarados, sin más intereses, recargos, ni multas.

Tal institución aúna dos aspectos: la valoración de un cierto arrepentimiento espontáneo ante la conducta ilícita realizada, y la tributación específica que supone. Es una regularización que pretende incrementar los ingresos públicos en un momento de crisis, en donde resulta necesario allegar fondos para cumplir con los criterios de estabilidad presupuestaria y reducción del déficit ${ }^{535}$. Se plantea así como una medida extrafiscal vinculada a la crisis económica. Con ella se busca que afloren bienes y derechos no declarados por los obligados, en definitiva, ocultados -la Disposición Adicional $1^{\circ}$ habla eufemísticamente de bienes o derechos que no se correspondan con la renta declarada-. Son bienes o derechos ubicados normalmente en paraísos fiscales, lugares en donde -al margen de una mejor tributación- resultan opacos a la Administración. Pero también posee una finalidad estrictamente fiscal, pues existe una tributación, aunque menor a la ordinaria, y permite mejorar el control futuro de los bienes declarados.

Dicha amnistía, ni es la primera ni, sin duda, será la última. Su admisión genera controversias sobre la eventual lesión al principio de igualdad ya que admite una menor tributación de quienes se acojan a la misma respecto a los sujetos que

${ }^{535}$ Así la Exposición de Motivos del Decreto Ley 12/2012 afirma que "También con el fin de reducir el déficit público, se establece una declaración tributaria especial para determinadas rentas y se adoptan medidas de carácter administrativo que contribuyan a generar ahorros en la gestión del patrimonio inmobiliario del sector público." 
habían cumplido sus obligaciones ${ }^{536}$. En la amnistía fiscal existe el peligro de premiar la ilicitud y desincentivar el cumplimiento legal y puntual. Su presupuesto de aplicación es una conducta ilícita: el haber ocultado bienes, ser titular de bienes y derechos que no se correspondan con los declarados. El régimen efectuado -pago del 10\% del valor de los mismos- supone un tratamiento más beneficioso que el otorgado a los contribuyentes cumplidores. En definitiva, resulta una regulación que trata de manera singularizada y beneficiosa a los sujetos incumplidores de sus obligaciones tributarias. Se evidencia una desigualdad de trato amparada jurídicamente en la posibilidad legal de condonar deudas (art. 75 de la LGT). Ahora bien, dicha justificación formal no es suficiente para evitar la discriminación que origina y que lesiona el principio de igualdad constitucionalizado en el art 31.1 de la CE. En tal sentido trata de manera diversa, y de forma más favorable, a los sujetos incumplidores de las normas tributarias y eventual infractores de las mismas.

La justificación material de tal medida -la extrafiscal de mejorar la recaudación- no resulta suficiente ni proporcionada para la consecuencia establecida. Es por ello que también cabe plantearse si la fiscalidad, y los principios que la informan, han de ceder ante exigencias no fiscales, o cual es el grado de instrumentalidad de la norma tributaria y la virtud de sus principios como límite al legislador.

\section{B. Las medidas preventivas y sus riesgos}

En los contextos actuales de gran movilidad e intercambio económico el Derecho ha de prever con antelación las conductas que le son lesivas. Así, existe una función preventiva en las normas que pretende anticipar y evitar determinadas situa-

\footnotetext{
536 Síntesis de la doctrina sobre el principio de igualdad ante la ley resulta la Sentencia del Tribunal Constitucional 76/1990, de 26 de abril [RTC 1990, 76], y establece: a) no toda desigualdad de trato en la ley supone una infracción del art. 14 de la Constitución, sino que dicha infracción la produce sólo aquella desigualdad que introduce una diferencia entre situaciones que pueden considerarse iguales y que carece de una justificación objetiva y razonable; b) el principio de igualdad exige que a iguales supuestos de hecho se apliquen iguales consecuencias jurídicas, debiendo considerarse iguales dos supuestos de hecho cuando la utilización o introducción de elementos diferenciadores sea arbitraria o carezca de fundamento racional; c) el principio de igualdad no prohíbe al legislador cualquier desigualdad de trato, sino sólo aquellas desigualdades que resulten artificiosas, o injustificadas por no venir fundadas en criterios objetivos y suficientemente razonables de acuerdo con criterios o juicios de valor generalmente aceptados; d) por último, para que la diferenciación resulte constitucionalmente lícita no basta con que lo sea el fin que con ella se persigue, sino que es indispensable además que las consecuencias jurídicas que resultan de tal distinción sean adecuadas y proporcionadas a dicho fin, de manera que la relación entre la medida adoptada, el resultado que se produce y el fin pretendido por el legislador superen un juicio de proporcionalidad en sede constitucional, evitando resultados especialmente gravosos o desmedidos.
} 
ciones que se consideran indeseables. Se regula expresamente, previniendo, situaciones que se consideran peligrosas por la proximidad a la lesión de un valor social. Por ello, respecto de conductas que se consideran de riesgo para el orden establecido y antes de la represión causante de la lesión al orden social, se arbitran medidas jurídicas para ser evitada. Son normas con una función de control cuya existencia conlleva una ampliación de los espacios del Estado para efectuar funciones de vigilancia e injerencia en la vida de los particulares.

El Derecho Tributario puede efectuar diversas funciones: de fomento, de carácter correctivo, y de prevención o disuasión. Desde la vertiente correctiva se pretende reequilibrar el incumplimiento de la obligación material o formal ocasionada. Y desde la faceta preventiva se pretende disuadir algunos comportamientos mediante el uso de diversas instituciones que, por sus efectos tributarios o consecuencias, sean adecuadas para tal fin. Atendiendo a esta última función podríamos hablar de un Derecho tributario preventivo integrado por un conjunto de normas que buscan que los incumplimientos tributarios no se produzcan, estableciendo medidas de control y desanimo para comportamientos que pueden resultar en abstracto peligrosos, sin que constituyan la imposición de una sanción.

Ahora bien, se ha de diferenciar nítidamente entre la prevención del incumplimiento tributario, de la que deriva la imposición de una sanción. La prevención del incumplimiento tributario es una cuestión propia de las normas de tal naturaleza, mientras que la prevención de la infracción es una cuestión netamente punitiva; se disuade del comportamiento infractor, y no del incumplimiento tributario.

La idea de prevención utilizada por el legislador tributario posee normalmente dos perspectivas: la que busca que los incumplimientos no se produzcan, estableciendo medidas de control administrativo basadas generalmente en nuevas fuentes de información; y el establecimiento de medidas jurídicas que, por sus consecuencias, disuadan del comportamiento a evitar. Dentro de las conductas disuasorias se integran un gran número de instituciones en donde se manifiestan diversos grados de ejercicio de la coacción, desde efectos subjetivos no deseados -que comportan mayores cargas materiales o gravámenes formales-, hasta medidas tendentes a reprimir la actuación indeseada, que suponen una lesión patrimonial y aproximan dicha medida a una sanción.

Las instituciones características de este Derecho tributario preventivo son, o bien cláusulas generales, o bien instituciones ad hoc. Las cláusulas pueden ser generales o específicas, y pretenden sobre todo evitar el fraude de ley. También se prevén instituciones tributarias específicas que pueden comportar diversas consecuencias: a) imponer un mayor gravamen, por ser conductas consideradas como no deseadas o peligrosas, valga como ejemplo los recargos tributarios o las ganancias no justificadas, b)poseer algunas consecuencias no deseadas, en particular, las valoraciones administrativas correctivas con efectos tributarios, c)gravar situaciones que no lo estarían a través de instituciones como la transparencia fiscal o las regulaciones 
asociadas a los paraísos fiscales, d)determinar una realidad jurídica diversa a la fáctica mediante las ficciones, o facilitar su determinación con las presunciones.

Las instituciones que conforman el Derecho tributario preventivo parten de un pronóstico de probabilidad que efectúa el legislador sobre el acaecimiento de una conducta lesiva. Ello comporta tener presente dos consideraciones generales. La primera, que el carácter de obligado tributario no comporte una presunción de peligrosidad. La segunda, que la medida a imponer sea proporcionada y no constituya sanción encubierta de la conducta considerada peligrosa.

La primera consideración parte de que la evaluación de dicha peligrosidad no puede efectuarse en juicios abstractos y genéricos, en donde la condición del obligado tributario sea determinante de la medida. El carácter de obligado tributario no puede cualificar al ciudadano de manera que resulte sospechoso, o presunto transgresor de la legalidad tributaria. En el ordenamiento rige el principio de buena fe, y de ahí que no quepa ignorar tal criterio como vector básico de la relación tributaria.

Respecto de la segunda consideración, la que alude a que la medida a imponer no ha de suponer una sanción o mal jurídico. La medida preventiva y la sanción obedecen a miradas y a juicios diversos. La culpabilidad supone un diagnostico con proyección al pasado y la peligrosidad un pronóstico con proyección al futuro. En tal sentido la culpabilidad supone un reproche, un juicio de valor, y la peligrosidad resulta un juicio de probabilidad de contenido fáctico vinculado a la realidad de las $\operatorname{cosas}^{537}$.

Las instituciones preventivas han de respetar la legalidad, preservando el principio de buena fe, pero también la proporcionalidad de sus efectos. Su regulación ha de suponer una evaluación realista del riesgo concurrente y ha de comportar una respuesta adecuada. Es necesario, en primer lugar, un pronóstico de la evasión tributaria que se proyecta hacia el futuro de una determinada situación fáctica. Es un juicio de probabilidad de que se concrete en lesión la situación peligrosa. En segundo lugar, es necesario que la medida empleada sea eficaz por su carácter disuasorio, sin que suponga la imposición de un mal.

Ahora bien, la exacerbación de una visión preventiva puede abocar a algunos riegos y distorsiones en la relación ciudadano-Administración a evitar.

$1^{\circ}$.La existencia de un deber de contribuir "más allá" de los derechos y libertades reconocidos, ¿sumisión ante la Administración?

La doctrina del Tribunal Constitucional ha puesto de relieve tal idea al afirmar que el deber de contribuir al sostenimiento de los gastos públicos establecido

${ }^{537}$ Traemos las palabras empleadas para diferenciar la peligrosidad penal que comporta la adopción de medidas de seguridad, de la culpabilidad que corresponde a la pena, así en ROMEO CASABONA, Carlos María. Peligrosidad y Derecho Penal preventivo. Barcelona: Bosch, 1986, p. 21. 
el artículo 31.1 CE, implica, "más allá del genérico sometimiento de la Constitución y al resto del ordenamiento jurídico que el artículo 9.1 de la norma constitucional impone, una situación de sujeción y de colaboración de los gastos públicos cuyo indiscutible y esencial interés público justifica la imposición de limitaciones legales al ejercicio de los derechos individuales" ${ }^{338}$. Tal afirmación corrobora, por un lado, el carácter fundamental del deber de contribuir. Así al hablar de su vinculación, más allá de las normas positivadas por el legislador, lo entronca con la dignidad de las personas -art. 10.1 de la CE-. Más, por otro lado, genera algunos interrogantes inquietantes ¿se busca una obediencia incondicional a los dictados normativos y a los requerimientos administrativos?, ¿la inconcreción y desmesura no puede llevarnos a un estado de sujeción más propio de súbditos que de ciudadanos? En todo caso, al amparo de tales afirmaciones no pueden crearse situaciones de sospecha generalizadas o la vigencia de principios denostados como el in dubio pro fiscum.

En el contexto tributario persisten manifestaciones impropias que aproximan al ciudadano a un estado de sujeción específico frente la Administración. Tal orientación se evidencia en diversas formulaciones, tanto de resoluciones de tribunales, como normativas ${ }^{539}$. En la relación jurídica tributaria el ciudadano no resulta súbdito, ni funcionario integrado en el orden interno administrativo. En la misma línea, no resulta adecuado la consideración y designación legal del administrado como obligado en el ámbito tributario (art. 35 de la LGT), pues también posee derechos. En tal denominación prevalece una visión de sujeción y vinculación que le inferioriza, pues denota la ausencia de una posición activa o de atribución.

\section{$2^{\circ}$.El peligro de la creación de realidades paralelas}

Las presunciones legales son medios de determinación de los hechos profusamente utilizados por el legislador tributario para prevenir el fraude. Es una institución que fija determinados hechos a partir de la prueba de otros entre los que existe un juicio lógico. Las presunciones legales han de ponderar sus efectos, de manera que no contribuya a crear una "para-realidad" jurídica que poco tenga que ver con la fáctica, e incluso, con la realidad jurídica concretada por otras ramas del Derecho.

Dichas presunciones han de ponderar el peligro que pretenden conjurar con los beneficios que reporta su actuación. Así, si el peligro es muy abstracto, más difícil será la justificación de su injerencia al alterar la normal conformación de los hechos en el ámbito probatorio. Se ha de tener presente que la presunción determina

\footnotetext{
${ }^{538}$ Así el FJ 13 de la Sentencia de 26 de abril de 1990 (RTC 1990, 76).

${ }^{539}$ Existen algunas resoluciones administrativas que afirman la existencia de tal vinculación, sobre todo en el seno de la infracción de resistencia, excusa u obstrucción a la actividad de la Administración. La Res. del TEAC de 26 de febrero de 1999 señala que "el incumplimiento del requerimiento hecho por la Administración es un acto [...]encuadrable en la desobediencia, un acto de policía tributaria, potestad de supremacía especial, no general[...]”.
} 
una realidad probable que sustituye la certeza otorgada por la prueba. De ahí que conformar tal probabilidad, sobre la base de sospechas de evasión o elusión, genere un clima de recelo poco propicio para la vigencia del principio de buena fe en las relaciones tributarias.

En tal sentido la existencia de medidas de prevención han de conjugarse con la exigencia de seguridad jurídica. Tanto en la idea de previsibilidad del gravamen, que toda institución jurídica conlleva, como en desterrar ámbitos de arbitrariedad de los poderes públicos. La ordenación que suponen tales medidas han de compatibilizar la seguridad de los individuos -las garantías de los derechos reconocidos- con la seguridad de la sociedad - los riesgos a la lesión de los deberes que genera la convivencia, en nuestro caso el de contribuir-.

Así las medidas preventivas establecidas han de suponer unas consecuencias previsibles, tanto por su establecimiento previo y claridad de su expresión, como por eliminar o sortear espacios de arbitrariedad de los poderes públicos. Desterrar arbitrariedad supone garantizar el reconocimiento de derechos, pero también la eficacia de las medidas establecidas, al evitar impugnaciones y favorecer su mejor aceptación.

\section{$3^{\circ}$.Presunción de mala fe y el in dubio pro fiscum}

La lucha contra el fraude no puede ignorar la vigencia de este ámbito, como en toda relación jurídica, del principio de buena fe. El principio de buena fe constituye un principio general del Derecho y en él se han de inspirar tanto los actos de la Administración como los de los administrados ${ }^{540}$. Aparece reconocido en el ordenamiento jurídico español en diversas manifestaciones, tanto del ámbito civil ${ }^{541}$ como del administrativo.

La buena fe es un principio general del Derecho que opera tanto desde la perspectiva del ejercicio de los derechos y potestades, como en el cumplimiento de deberes, ya sea por la Administración, ya por los administrados. Dicha afirmación "conlleva la necesidad de una conducta leal, honesta, aquella conducta que, según la

\footnotetext{
${ }^{540}$ Ver PONT MESTRES, Magín. "En torno a la ausencia de presunción de buena fe del contribuyente en la Ley General Tributaria”, Quincena Fiscal, n 19, 2004 [consultado en el servicio westlaw el 15 de julio de 2013]. Dicho autor define a la buena fe como "una actitud de honradez, confianza y fiabilidad dentro y fuera del Derecho, si bien en el seno de éste tal actitud lo es en su proyección en las relaciones jurídicas en que interviene, que es cuando se manifiesta, por lo que ha de valorarse en cada caso concreto."

${ }^{541}$ El Código civil señala que los derechos han de ejercitarse de acuerdo con la buena fe, estableciendo dicho criterio de manera imperativa. No cumplir tal exigencia, sobrepasando manifiestamente los límites normales del ejercicio de un derecho con daño a terceros, es abusar de la posición jurídica. Su consecuencia es la adopción de medidas que impidan la persistencia del abuso y el establecimiento de las correspondientes indemnizaciones -art. 7 del Cc-.
} 
estimación de la gente, puede esperarse de una persona"542. La existencia de la vinculación de la Administración al derecho (principio de legalidad) no resulta óbice para su reconocimiento, pues el principio de legalidad es sólo uno de los elementos del Estado de Derecho, y el principio de la buena fe supone el reconocimiento jurídico del valor ético social de la confianza, es elemento esencial para la paz y la seguridad jurídica ${ }^{543}$.

La buena fe tiene una honda tradición jurídica que aporta seguridad y claridad a la hora de explicar las posiciones subjetivas en las relaciones jurídicas. Dicho criterio cohonesta y aquilata una interpretación equilibrada de los intereses que han de protegerse, los de la Administración y los del administrado. De aquí se deriva que no cabe partir de apriorismos respecto de la prevalencia de unos u otros intereses a la hora de efectuar la exegesis normativa: ni presumir la mala fe, ni preferir los intereses de una de las partes.

\section{por el contribuyente}

$4^{o}$. La privatización de tareas y la internalización de responsabilidades

La privatización ${ }^{544}$ de la gestión tributaria ha conllevado la proliferación de obligaciones formales a cargo del obligado y la ubicación de las tareas administrativas en una fase posterior, de control. Dicha privatización se pone en evidencia con el establecimiento de un conjunto de vinculaciones que concurren en la obligación de autoliquidar. La autoliquidación implica una obligación de declarar -de comunicar unos hechos a la Administración-, de calificar jurídicamente tales acontecimientos facticos, de cuantificar el importe del tributo y de efectuar, eventualmente, el ingreso ${ }^{545}$. El sistema de autoliquidación se fundamenta en el protagonismo del

${ }^{542}$ GONZÁLEZ PÉREZ, Jesús. El principio general de la buena fe en el Derecho administrativo. $4^{\mathrm{a}}$ edición. Madrid: Civitas, 2004, p. 91.

543 PONT MESTRES, Magín. "En torno a la ausencia de presunción de buena fe del contribuyente en la Ley General Tributaria”, Quincena Fiscal, n 19, 2004 [consultado en el servicio westlaw el 15 de julio de 2013].

${ }^{544}$ Expresión acuñada por FERREIRO LAPATZA, José Juan. ’La privatización de la gestión tributaria y las nuevas competencias de los Tribunales Económico- Administrativos", Revista Española de Derecho Financiero, no 37, 1983, p. 84 y 85.

545 SAINZ DE BUJANDA señalaba que el esquema del procedimiento de liquidación tradicional estaba basado en declaración/ liquidación provisional/ comprobación/ liquidación definitiva y es el "propio de un sistema tributario en el que el número de contribuyentes no es excesivamente elevado y que permite una cierta complejidad en las actuaciones administrativas, resulta excesivamente lento y costoso cuando el sistema se convierte en un sistema "masivo" en el que aumenta de forma muy importante tanto el número de los contribuyentes como, en su consecuencia, las declaraciones que han de ser controladas y liquidadas". (SAINZ DE BUJANDA, Fernando. Lecciones de Derecho Financiero. 10 a Edición, Madrid: 
contribuyente, ya que la Administración ha desplazado hacia los contribuyentes el cumplimiento de las tareas que tradicionalmente tenía encomendadas en los procedimientos de aplicación de los tributos. El contribuyente no solamente declara los hechos realizados, sino además liquida el tributo. Correlativo a dicha asunción de tareas gestoras por el particular la actividad de la Administración tributaria pasa, de centrarse en tareas de liquidación, a tareas de comprobación y control de la actividad del contribuyente. En tal esquema la aplicación del sistema tributario descansa, en buena medida, en la actividad del sujeto pasivo, reservándose la Administración el control de lo efectuado mediante la comprobación e investigación ${ }^{546}$.

Tal fenómeno conlleva también una internalización de la responsabilidad en la aplicación de los tributos. La misma para de que es el propio contribuyente el que ha de aplicar normas cuyo conocimiento resulta difícil, dado su dinamismo y volumen masivo de producción.

A nadie sorprende el afirmar y proclamar lo cambiantes, confusas y complicadas que resultan las leyes tributarias, ni tan siquiera los expertos están seguros de conocerlas todas y bien. Con tal panorama la pregunta inmediata que se origina es ¿cómo se logra tan compleja aplicación?, ¿mediante una Administración con conocimientos superlativos sobre la materia? No parece ser esta la respuesta, pues buena parte de sus tareas se han privatizado encomendándose a la ciudadanía. Por ello, de una parte, es ésta quien debe calificar jurídicamente las rentas, cuantificar, e ingresar la mayoría de los tributos. Pero también, de otra parte, respecto de las tareas que todavía desempeña la Administración, se llevan a cabo por funcionarios cuya formación de base resulta ajena a ciencias jurídicas (físicos, economistas, ingenieros...). Pero, entonces, ¿cómo pueden dichos funcionarios aplicar tales normas que tildamos de complejas? Dicha aplicación descansa en la existencia de catálogos de practicas simplificados que unifican actuaciones administrativas, que son dictados a través de circulares y resoluciones administrativas. O sea, el criterio directamente aplicable no son las fuentes del Derecho, sino mandatos jerárquicos. Ello lleva a que más que resolver sobre la base de la norma se resuelva sobre catálogos de soluciones de casos concretos. Con ello la ley y el reglamento sufren un proceso de posposición.

Tal deterioro aplicativo se ve retroalimentado por un legislador especialmente sensible a los concretos problemas administrativos de ahí que, en demasiadas ocasiones, sus leyes pretendan más solucionar prácticas concretas que efectuar regu-

Universidad Complutense, 1993, p. 312).

${ }^{546}$ A este respecto CASADO OLLERO apunta una cierta tendencia a la "“"subsidiariedad" de la actividad administrativa tributaria, en cuanto resulta relegada a una actividad de control y sólo se materializa formalmente para "suplir" la actuación del contribuyente, para "integrarla" cuando parezca insuficiente o para "rectificarla" y "sancionarla", cuando aquélla resulte irregular." (CASADO OLLERO, Gabriel. "La colaboración con la Administración tributaria. Notas para un nuevo modelo de relaciones con el fisco", Hacienda Pública Español, n 68, 1981, p. 170). 
laciones con perspectivas genéricas y sistémicas.

También, al encomendar buena parte de dicha aplicación a los particulares, puede llevarnos a pensar: cuán instruidos que son nuestros ciudadanos que conocen y aplican leyes tan complejas. Pero ello tampoco es así, o no es totalmente de esta manera, la ciudadanía asume la responsabilidad de su aplicación, pero quien realmente aplica la norma son los asesores fiscales. Ahora bien, éstos se encuentran tan perdidos en el marasmo normativo y en las dificultades de su entendimiento que acuden a los funcionarios y a las prácticas de la Administración para encontrar seguridad. Las personas que no poseen los suficientes recursos para acudir a tales asesores técnicos, siempre podrán acudir a la Administración a pedir información y asistencia -art. 85 de la LGT- y ésta les indicará.

Con ello, como puede apreciarse, se cierra un circulo en el que la norma tributaria acaba por ser aplicada, directa o indirectamente, por la Administración. Y en todo este itinerario, ¿qué ha variado de la tradicional aplicación y liquidación del tributo por la Administración, pues ésta continúa teniendo un papel básico en la calificación jurídica? La variación ha sido sustancial, pues ha comportado un proceso de internalización de la responsabilidad de la aplicación del tributo por la ciudadanía. No es la Administración quien asume las consecuencias de su aplicación, pero sí decide sustancialmente los criterios aplicativos.

En tal esquema existe una variación a tener presente que afecta a la justicia del sistema, pues los sujetos que tienen mayores recursos pueden acudir a asesores jurídicos, a buenos conocedores de la normativa para que diseñen operaciones que aprovechen los resquicios de tales leyes imperfectas. Para éstos los defectos de las leyes y la diversidad de tratamientos internacionales en contextos de globalización son espacios de oportunidad. Tal situación conforma un contexto en donde la tradicional desigualdad, de base económica, se reitera y amplifica. A mayor capacidad económica se constatan las mayores capacidades para eludir la aplicación de la carga tributaria justa.

\section{Conclusiones}

De lo expuesto, y aras de sintetizar las principales ideas sustentadas cabe concluir:

$1^{\circ}$.El deber de contribuir resulta una vinculación normativa de carácter valorativo y contenido ético. Si bien la tributación es contemplada habitualmente como un mero costo, la deuda fiscal también expresa y vehicula el valor de solidaridad ciudadana. El deber de contribuir no sólo es límite, también se basa en el valor de solidaridad ínsito y connatural de las sociedades en que se reconocen derechos fundamentales. Solidaridad que, como valor y deber, posee una estrecha relación con los derechos reconocidos. 
$2^{\circ}$.La afirmación del carácter fundamental del deber de contribuir, al igual que los derechos así considerados, se basa en su imbricación con la dignidad de la persona. Dignidad como garantía de condiciones físicas y materiales de la persona sin cuyo reconocimiento no puede ser considerada como tal. Para garantizar tanto la dignidad existencial como la dignidad en las condiciones materiales de vida se precisa de la solidaridad de los miembros de una comunidad. Solidaridad cuya manifestación más importante en las sociedades contemporáneas se arbitra a través del deber de contribuir a los gastos públicos. Resulta así que dicho deber deviene fundamental para garantizar la eficacia y el reconocimiento material de los derechos de las personas.

$3^{\circ}$. La tributación justa resulta presupuesto material para el reconocimiento de unos estándares de derechos individuales y sociales. Existe una clara correlación entre el deber de contribuir y los derechos fundamentales, sobre todo los de carácter prestacional, por lo que dejar de cumplir tal deber erosiona la eficacia de tales derechos. El deber de contribuir resulta el presupuesto material para la garantizar el ejercicio de derechos humanos y sociales, no tan sólo propios, sino de los conciudadanos, lo cual le confiere una especial dimensión solidaria.

$4^{\circ}$.La exigencia de tal deber, como correlato a su reconocimiento, ha de obedecer a criterios éticos y de valor acordes, recogidos normalmente a través de principios constitucionales. Atendiendo a tal consideración de valor resultan criticables las medidas que puedan originar discriminaciones como las amnistías. En concreto, la justificación material de tal medida -la extrafiscal de mejorar la recaudación- no resulta suficiente ni proporcionada para la consecuencia establecida. Es por ello que también cabe plantearse si la fiscalidad, y los principios que la informan, han de ceder ante exigencias no fiscales, o cual es el grado de instrumentalidad de la norma tributaria y la virtud de sus principios como límite al legislador.

$5^{\circ}$.Los contextos actuales demandan el establecimiento de medidas preventivas del fraude que, con carácter previo a la lesión del deber, anticipen soluciones adecuadas. Las instituciones preventivas han de suponer una evaluación realista del riesgo concurrente y han de comportar una respuesta adecuada. De ahí que sea necesario, en primer lugar, un pronóstico de la evasión tributaria que se proyecta hacia el futuro de una determinada situación fáctica. Es un juicio de probabilidad de que se concrete en lesión la situación peligrosa. En segundo lugar, es necesario que la medida empleada sea eficaz por su carácter disuasorio, sin que suponga la imposición de un mal. 
Ahora bien, tales medidas no han de suponer:

a) La afirmación de estados de sujeción más propios de súbditos que de ciudadanos.

b) La creación de realidades paralelas lesivas.

c) La presunción de mala fe en la conducta del ciudadano.

d) El sometimiento cargas de gestión exorbitantes y desproporcionadas.

\section{Bibliografía}

CAZORLA PRIETO, Luís María. Derecho Financiero y Tributario. Parte General. Pamplona: Aranzadi, 2002.

CASADO OLLERO, Gabriel. "La colaboración con la Administración tributaria. Notas para un nuevo modelo de relaciones con el fisco", Hacienda Pública Español, $\mathrm{n}^{\mathrm{o}} 68,1981$.

BAYONA DE PEROGORDO, Juan José y SOLER ROCH, María Teresa. Compendio de Derecho Financiero. Alicante: Librería Compas, 1991.

DELGADO LOBO, María Luisa, FERNÁNDEZ-CUARTERO PARAMIO, Marta, MALDONADO GARCÍA-VERDUGO, Ascensión, ROLDAN MUÑIO, Concepción y VALDENEBRO GARCÍA, María Luisa. La educción fiscal en España. Doc. $n^{\circ}$ 29/05. Madrid: Instituto de Estudios Fiscales, 2005.

DIÉZ PICAZO, Luís María. Sistema de derechos fundamentales. $4^{a}$ edición. Madrid: Civitas Thonsom-Reuters, 2013.

FERREIRO LAPATZA, José Juan. "La privatización de la gestión tributaria y las nuevas competencias de los Tribunales Económico- Administrativos", Revista Española de Derecho Financiero, n 37, 1983.

GARCIA DE ENTERRIA, Enrique. y FERNANDEZ, Tomás Ramón. Curso de Derecho Administrativo. Vol I. Madrid: Civitas, 1995.

GOMEZ SANCHEZ, Yolanda. "Dignidad y ordenamiento comunitario" en Revista de Derecho Constitucional Europeo, ${ }^{\circ}$ 4, 2005, [consultado: 4 junio 2014] Disponible en internet en http://www.ugr.es/ redce/REDCE4/articulos/09yolanda.htm.

GONZÁLEZ PÉREZ, Jesús. El principio general de la buena fe en el Derecho administrativo. $4^{\text {a }}$ edición. Madrid: Civitas, 2004.

Jornadas XX Jornadas Latinoamericanas de Derecho Tributario, Salvador (Bahía) - Brasil, 2000, [consultado 5 junio 2014]. Disponible en: http://www.iladt.org/frontend/ResolutionPage.aspx.

MARTINEZ MORÁN, Narciso y DE CASTRO CID, Benito (Coordinadores). Die- 
cisiete lecciones de Teoría del Derecho. 2a edición, Madrid: Uned Editorial Universitas, 2011.

MARTIN QUERALT, Juan, LOZANO SERRANO, Carmelo, TEJERIZO LOPEZ, José Manuel y CASADO OLLERO, Gabriel. Curso de Derecho Financiero y Tributario. Madrid: Tecnos. 2007.

PALOMBELLA, Gianluigi. "De los derechos y de su relación con los deberes y los fines comunes". Derechos y libertades, n 17, época II, junio 2007.

PECES-BARBA MARTINEZ, Gregorio. Lecciones de Derecho Fundamentales. Madrid: Dykinson. 2004.

PEREZ LUÑO, Antonio Enrique. Los derechos fundamentales. $8^{\text {a }}$ edición, Madrid: Tecnos. 2004.

PEREZ ROYO, Fernando. Derechos Financiero y tributario. Parte General. Madrid: Thonson-Civitas. 2005.

PONT MESTRES, Magín. "En torno a la ausencia de presunción de buena fe del contribuyente en la Ley General Tributaria", Quincena Fiscal, n 19, 2004 [consultado en el servicio westlaw el 15 de julio de 2013].

RODRIGUEZ PALOP, María Eugenia. Claves para entender los nuevos derechos humanos. Madrid: Catarata. 2011.

ROMEO CASABONA, Carlos María. Peligrosidad y Derecho Penal preventivo. Barcelona: Bosch, 1986.

ROZAS VALDÉS, José Andrés. "Nota preliminar", en Franco GALLO. Las razones del Fisco. Ética y justicia en los tributos. Madrid: Marcial Pons, 2012.

SAINZ DE BUJANDA, Fernando. Lecciones de Derecho Financiero. 10 ${ }^{\text {a }}$ Edición, Madrid: Universidad Complutense, 1993.

TIPKE, Klaus. Moral tributaria del Estado y de los contribuyentes. Madrid: Marcial Pons, 2002.

VALLEJO CHAMORRO, José $\mathrm{M}^{\mathrm{a}}$. "La competencia fiscal perniciosa en el seno de la OCDE y la Unión Europea”. Revista de economía. nº 825, 2005.

VARONA ALABERN, Juan Enrique. Extrafiscalidad y dogmática tributaria. Madrid: Marcial Pons, 2009.

ZAGREBELSKY, Gustavo. El derecho dúctil. Ley, derechos, justicia. Madrid: Editorial Trotta. 2009. 